\title{
Factors that Inhibit Sustainable Adoption of Industry 4.0 in the South African Manufacturing Industry
}

\author{
Whisper Maisiri ${ }^{1, * \mathbb{C}}$, Liezl van Dyk ${ }^{2}$ and Rojanette Coeztee ${ }^{1}[$ \\ 1 School of Industrial Engineering, North-West University, Potchefstroom 2531, South Africa; \\ Rojanette.Coetzee@nwu.ac.za \\ 2 Faculty of Engineering, North-West University, Potchefstroom 2531, South Africa; Liezl.VanDyk@nwu.ac.za \\ * Correspondence: 25727265@nwu.ac.za; Tel.: +27-18-285-2659 or +27-73-049-7536
}

check for

updates

Citation: Maisiri, W.; van Dyk, L.;

Coeztee, R. Factors that Inhibit

Sustainable Adoption of Industry 4.0 in the South African Manufacturing Industry. Sustainability 2021, 13, 1013 https://doi.org/10.3390/su13031013

Received: 9 November 2020

Accepted: 9 January 2021

Published: 20 January 2021

Publisher's Note: MDPI stays neutral with regard to jurisdictional clai$\mathrm{ms}$ in published maps and institutional affiliations.

Copyright: $(\odot 2021$ by the authors. Licensee MDPI, Basel, Switzerland. This article is an open access article distributed under the terms and conditions of the Creative Commons Attribution (CC BY) license (https:// creativecommons.org/licenses/by/ $4.0 /)$.

\begin{abstract}
Industry 4.0 (I4.0) adoption in the manufacturing industry is on the rise across the world, resulting in increased empirical research on barriers and drivers to I4.0 adoption in specific country contexts. However, no similar studies are available that focus on the South African manufacturing industry. Our small-scale interview-based qualitative descriptive study aimed at identifying factors that may inhibit sustainable adoption of I4.0 in the country's manufacturing industry. The study probed the views and opinions of 16 managers and specialists in the industry, as well as others in supportive roles. Two themes emerged from the thematic analysis: factors that inhibit sustainable adoption of I4.0 and strategies that promote I4.0 adoption in the South African manufacturing industry. The interviews highlighted cultural construct, structural inequalities, noticeable youth unemployment, fragmented task environment, and deficiencies in the education system as key inhibitors. Key strategies identified to promote sustainable adoption of I4.0 include understanding context and applying relevant technologies, strengthening policy and regulatory space, overhauling the education system, and focusing on primary manufacturing. The study offers direction for broader investigations of the specific inhibitors to sustainable I4.0 adoption in the sub-Saharan African developing countries and the strategies for overcoming them.
\end{abstract}

Keywords: Industry 4.0; sustainability; manufacturing industry; South Africa; technology adoption drivers; technology adoption barriers; qualitative descriptive study

\section{Introduction}

Adoption of Industry 4.0 (I4.0) has been on the rise in developed countries' manufacturing industries, with other developing countries, such as China and India, following suit. The term I4.0 was coined in Germany in 2011, and its principles were adopted to enhance the competitiveness and growth of the national manufacturing industry [1-3]. The subsequent wide-ranging adoption of this approach recognizes it as an enhancer of competitiveness and growth in the manufacturing industry [4,5].

Although acknowledged globally, the adoption of I4.0 in South Africa has not been analyzed in the literature. Its many benefits in the country could include enhancing global competitiveness and boosting productivity and revenue growth of the manufacturing industry [4,5]. The adoption of I4.0 therefore attracts significant interest from sectors related to and supporting the manufacturing industry, including the digital industry, public sector, research and development, and non-governmental organizations (NGOs). However, the adoption of I4.0 also has the potential of widening global inequality among and within countries, and could hinder the achievement of the United Nations 2015 sustainable development goals (SDGs) [6]. In particular, I4.0 could detrimentally affect the achievement of SDG 8 (the promotion of sustained, inclusive, and sustainable economic growth, full and productive employment, and decent work for all), SDG 9 (inclusive and sustainable industrialization), and SDG 10 (reduction of inequality within and among countries) [7] in developing countries [8]. 
Industry 4.0 is not a one-size-fits-all framework, and a geographic lens is necessary when exploring relevant barriers and driving factors $[9,10]$. An increasing number of studies have focused on the drivers and barriers to I4.0 adoption in various developed and developing countries [9,11-13], but none so far in South Africa. This is one of several developing countries moving towards convergence with developed country standards [14], and has the potential of becoming a leader for sustainable adoption of I4.0 in the manufacturing industry sector in sub-Saharan Africa. The country also played an active role in the development of the SDGs, and is committed to the efforts needed to meet these goals [15]. Thus, it could illuminate the benefits of I4.0 adoption and introduce strategies for identifying and mitigating its potential negative impacts on SDGs, thereby acting as a benchmark in the region. Understanding the contextualized barriers in the country, as well as the drivers of sustainable adoption of I4.0, could be the first step towards the achievement of both I4.0 and SDGs.

The South African manufacturing industry has been shrinking over the past two or more decades. Its share of the country's gross domestic product decreased from $19.3 \%$ in 1994 to $12 \%$ in 2018 [15]. Notably, the industry employs both semi-skilled and low-skilled employees [16]. Adoption of the I4.0 initiative [17-19] could therefore pose significant challenges when balancing the manufacturing industry's attempts both to catch up and keep pace with developed countries and to address the issue of unemployment in its fields of operation $[20,21]$. In seeking ways to strike this balance, it is important to explore contextual factors that currently inhibit sustainable adoption of I4.0.

South Africa also faces socioeconomic challenges, including non-inclusive economic growth and inequality $[15,22,23]$. To address them, the South African government launched the national development plan (NDP) in 2012, which aimed at fighting poverty, inequality, and unemployment and at growing an inclusive economy [15,24]. This NDP predated the SDGs, but has a high $(74 \%)$ correlation to them $[15,24]$. Both the SDGs and South Africa's NDP feature and emphasize an end to poverty, protection of the environment, and inclusive prosperity $[7,15]$. Achieving sustainability in the South African manufacturing industry through I4.0, therefore, requires that its adoption aligns with the objectives of the NDP and the SDGs. This challenge can be addressed most effectively if factors that inhibit sustainable adoption of I4.0 in the country are properly understood within the specific national context.

Barriers and drivers pointed out in existing studies $[2,4,5,9-13,25,26]$, such as lack of ICT infrastructure, lack of standards, data security concerns, high investment requirements, skills shortages, lack of regulatory framework, and lack of implementation strategy, could apply to the South Africa manufacturing industry. However, factors unique to the country could inhibit sustainable adoption of I4.0. Public and private sector workshops, seminars, and conferences on I4.0 and the fourth industrial revolution are noticeably on the rise in the country [27]. However, there is a lack of empirical studies focusing on the South African manufacturing industry context [28-31]. To address this gap, we designed a smallscale interview-based exploratory qualitative study to identify factors that could inhibit sustainable adoption of I4.0 in the country's manufacturing sectors. Interviews offered us the opportunity to gather the views of individuals whose work was relevant to I4.0 adoption in these sectors. Participants came from sectors that provide support and have an interest in manufacturing, such as the digital industry, the research and development sector, the public sector, and relevant NGOs. Those taking part provided perspectives from management as well as a content expert perspective. We aimed to obtain a sense of the direction that I4.0 adoption might take in South African manufacturing, and to explore nuances specific to this context that, to date, have not been identified in the academic literature. The study was guided by the research question: what are the factors that inhibit sustainable adoption of I4.0 in the South Africa manufacturing industry?

The remainder of this article is structured as follows: Section 2 presents a theoretical background to sustainable technology adoption in the manufacturing industry and a literature overview on worldwide barriers and drivers to I4.0 adoption; Section 3 presents 
the empirical setting together with data collection and data analysis; Section 4 presents the study results, which are discussed in Section 5 and lead to the study limitations and direction for future research; Section 6 concludes the study.

\section{Theoretical Background and Literature Review}

The countries that are signatories to the UN's 2015 Sustainable Development 2030 agenda face the challenge of achieving its 17 goals [7,32]. According to Fu et al. [32], sustainable technology adoption could facilitate their meeting the SDGs, and has attracted interest from both society and academia [32]. However, studies relating to sustainable technology adoption have focused mainly on SDGs related to the environment and economics, and less on its social aspects.

Sustainable technology adoption following the I4.0 framework includes the adoption of technologies such as cyber-physical systems, the internet of things, additive manufacturing, and autonomous robotics [2,3,33]. Sony and Naik [34] pointed out that such adoption is regarded as sustainable if it balances the environmental, economic, and social needs of present and future generations [34], and Müller et al. [12] have stressed the need to balance the environmental, economic, and social aspects of sustainability when adopting I4.0 technologies. These principles also apply to technology adoption in the manufacturing industry [4,35-37].

Müller et al. [12] pointed out that the current literature predominantly investigated the impact of I4.0 from a single technological adoption sustainability aspect [12]. Adoption of I4.0 technologies in manufacturing has significantly focused on economic sustainability, competitiveness, and growth [1-3]. Other studies that focused on environmental sustainability are exemplified by de Sousa Jabbour et al. [38], who pointed out the need for balancing I4.0 adoption and environmental sustainability. Müller et al. [12] addressed the balancing of environmental and economic sustainability in Germany's manufacturing industry. The developing country context of I4.0, however, has not so far been examined from the social sustainability standpoint.

Existing studies have already revealed the societal advantages of technology adoption in developing countries, such as, for example, in the application of big data and big data analytics to mitigate the effects of disease outbreaks [39] to foster informed decisionmaking in private and public spheres in this area, and to improve predictive capacity when planning for future requirements. Studies are still lacking, however, that investigate I4.0 adoption in manufacturing, taking into account the satisfaction of broader social, economic, and environmental issues that could otherwise undermine sustainability in developing countries. To address this gap, our study sought to gain an understanding of factors that could inhibit I4.0 adoption within the specific context of the South African manufacturing industry in terms of the balance between competitiveness in manufacturing, on the one hand, and societal aspects of such adoption in this developing country, on the other hand, in the light of pervasive inequality and unemployment.

\subsection{Barriers and Drivers Relating to Industry 4.0 Adoption}

Industry 4.0 was initially conceived with the object of increasing Germany's global technological innovation competitiveness [13,40,41] and optimizing value creation in its manufacturing industry. The strategy is associated with the employment of advanced technologies in manufacturing, and the term is used to describe advances in the application of digitalization, automation, and creation of digital value chains [17-19].

There has been growth in empirical research on barriers and drivers to I4.0 in various country settings, including Romania [11], Hungary [9], Germany [2,12], India [10,13], China [41], and Denmark [25]. The studies presented here (Table 1) were selected for their detailed contributions to the understanding of factors influencing the adoption of I4.0. 
Table 1. Barriers and drivers to I4.0 adoption literature overview.

\begin{tabular}{ccc}
\hline Author(s) Reference & Study Focus and Setting & Key Contributions \\
\hline Kumar et al., 2020 [5] & $\begin{array}{c}\text { Analyzing the barriers to I4.0 } \\
\text { through the best-worst } \\
\text { method for Indian industry }\end{array}$ & $\begin{array}{c}\text { Ranking of the barriers to I4.0 } \\
\text { adoption using the } \\
\text { best-worst method }\end{array}$
\end{tabular}

Drivers and Barriers

Barriers: lack of ICT infrastructure, lack of standards, data security concerns, high investment requirements, skills shortages, lack of regulatory framework, unwanted strain, no manpower.

Stentoft et al., 2020 [25] $\quad \begin{gathered}\text { Drivers and barriers to I4.0 } \\ \text { readiness and practice in } \\ \text { Danish SME manufacturers }\end{gathered}$
Demonstration of the difficulties faced by SMEs in achieving $I 4.0$ readiness

Drivers: legal requirements, customer requirements, cost reduction, optimized time to market Barriers: lack of standards, shortage of financial resources, lack of skills, awareness challenges

Driver: competitiveness, improved information sharing system and resource development, adoption of innovative business models, collaboration and transparency

Barriers: lack of competence, Workers' perspective on Insights on barriers to I4.0, concerns hampering I4.0 Müller 2019 [2] implementation in Germany industrial enterprise

from workers' point of view, which can be utilized by management employee resistance to change, lack of implementation strategy, unclear benefits to workers, automation taking decisions from humans Examination of the Challenges to I4.0 adoption challenges of regression model and use of

Prause 2019 [26] I4.0 adoption by Japanese SME manufacturing firms

Cronbach's alpha to test its reliability

Barriers: lack of knowledge, complexity of I4.0, high

implementation cost, market uncertainty, security concerns

Drivers: increased efficiency, product quality, global competitiveness

Investigation of drivers and barriers to I4.0 implementation in Romanian SMEs
Identified barriers and drivers to I4.0 implementation in Romania SMEs
Barriers: lack of expertise, regulations and working procedures in developing countries, lack of standards

Barriers: high investment cost, insufficient data and information security, lack of infrastructure, inequality, digital skills shortages, lack of standards and regulations, resistance to change

Drivers: workforce challenges due

to aging population in developed countries, raising global competitiveness

Comparison of barriers and exploring how company

Horváth and Szabó driving forces and barriers to 2019 [9] drivers to I4.0 between SMEs and multinational companies
The total degree of influence that barriers to I4.0

implementation have on each other using the

Grey-DEMATEL approach
Barriers: lack of skilled workforce,
I4.0 implementation in Hungary insufficient data security, organizational resistance 
Table 1. Cont.

\begin{tabular}{|c|c|c|c|}
\hline Author(s) Reference & Study Focus and Setting & Key Contributions & Drivers and Barriers \\
\hline Müller et al., 2018 [12] & $\begin{array}{l}\text { Examining I } 4.0 \text { opportunities } \\
\text { and challenges in Germany's } \\
\text { manufacturing industry }\end{array}$ & $\begin{array}{l}\text { Categorical ranking of I4.0 } \\
\text { adoption challenges/barriers }\end{array}$ & $\begin{array}{l}\text { Drivers: strategic and business } \\
\text { model opportunities that maintain } \\
\text { and expand competitiveness, } \\
\text { enhanced efficiency, timing, } \\
\text { flexibility, and quality } \\
\text { Barriers: complexity of integrating } \\
\text { I4.0 technologies }\end{array}$ \\
\hline Kamble et al., 2018 [13] & $\begin{array}{l}\text { Analyzing the potential } \\
\text { barriers to I4.0 in Indian } \\
\text { manufacturing organizations }\end{array}$ & $\begin{array}{l}\text { Establishment of barriers to an } \\
\text { I4.0 relationship and } \\
\text { dependence power and } \\
\text { development of hierarchical } \\
\text { relationships of these barriers }\end{array}$ & $\begin{array}{l}\text { Barriers: legal and contractual } \\
\text { challenges, employment } \\
\text { disruptions, need to enhance skills } \\
\text { requirements, lack of ICT } \\
\text { infrastructure, insufficient security } \\
\text { and privacy, regulatory challenges, } \\
\text { implementation cost, lack } \\
\text { of awareness }\end{array}$ \\
\hline
\end{tabular}

The country-based studies in the literature present drivers and barriers to I4.0 adoption in developed and developing countries, but none examine drivers and barriers to such adoption in sub-Saharan African developing countries. This study seeks to close this gap by investigating factors that inhibit sustainable I4.0 adoption in the South African manufacturing industry.

\subsection{Industry 4.0, South Africa's National Development Plan, and the Sustainable Development Goals}

The SDGs were crafted and adopted by the United Nations in 2015 [42] to drive development towards balancing the "dimensions of sustainable development: economy, social, and environment" globally [7]. This aligns with the objective of South Africa's NDP "to eliminate poverty and reduce inequality" [7,24].

The emerging of I4.0 has centered on enhancing competitiveness, productivity, and revenue growth [43]. Its value creation capability, therefore, has the potential to contribute to the achievement of SDG goals [42], such as SDG 12 ("ensure sustainable consumption and production patterns") [7], which corresponds to the NDP's Chapter 5 objective of environmental sustainability and resilience [24]. Bonilla et al. [43] pointed out that I4.0 could positively drive SDGs related to environmental sustainability, provided that technology is innovated to meet the country's requirements and supportive policies are put in place [43]. Technological advancement has been recognized for its potential to solve social and economic challenges faced by developing countries $[39,44,45]$. The adoption of I4.0 in a country, therefore, needs to be underpinned by well-developed and balanced policies to help it achieve both competitiveness and inclusivity.

Adopting I4.0, however, poses significant challenges and risks to aspects of inclusive development and the reduction of inequality outlined in the NDP and the SDGs [8]. Van Niekerk [6] viewed technological advancements as one of the drivers of inequality within and among countries [6]. Thus, I4.0 could potentially hinder the achievement of SDG 10 ("reduce inequality within and among countries") [7,8]. SDG 10 is aligned with the NDP's Chapter 11 (social protection).

With I4.0 comes increased job complexity requiring specialized skills [31,46,47], which makes significant demands on the manufacturing industry's skills requirements. Accordingly, the adoption of I4.0 could result in compromising achieving SDG 8 [8] (promote sustained, inclusive, and sustainable economic growth, full and productive employment, and decent work for all) [7], which aligns with NDP Chapter 3 (economy and employment) [24]. Furthermore, developing countries have a less competitive advantage in achieving SDG 9 (inclusive and sustainable industrialization) [7,8], which aligns with NDP Chapter 4 (economic infrastructure) [24]. 
The literature relating to I4.0, read together with the developing country aims embedded in South Africa's NDP and the UN's SDGs, suggests that I4.0 adoption in the South African manufacturing industry requires customized supportive innovations and policies around technological development. Understanding the factors that could inhibit I4.0 adoption or undermine the broader national aims is therefore important for facilitating, designing, and developing the supportive policies needed for success.

\section{Method}

The research focused on exploring contextual factors that inhibit the sustainable adoption of I4.0 in the South African manufacturing industry. It followed a qualitative descriptive interview-based approach [48-50] to collect views and opinions from participants who represented different facets of the manufacturing industry about the adoption of I4.0 in this industry in South Africa.

\subsection{Research Setting and Participants Sampling}

The study was undertaken using semi-structured interviews with participants at management and specialist expert levels in the manufacturing and digital industries in order to obtain rich data. We included further relevant role-players from the research and development sector, public sector, and non-governmental organizations that provide support and have a special interest in manufacturing. The aim was to obtain a relevant interdisciplinary range of views and opinions.

Purposeful sampling, commonly employed in qualitative descriptive studies [51,52], was used to select the study participants based on the following inclusion criteria: practicing within South Africa; involvement in and contribution to I4.0 workshops, conferences, and online I4.0 platforms; and the participant's current position as a decision-maker or expert. The participants from the manufacturing industry came from organizations that had already adopted or were in the process of adopting I4.0, and were selected for their ability to provide informed opinions on factors that affect its sustainable adoption. The participants from the digital industry were working with I4.0 technologies and were involved in assisting manufacturing companies in the adoption journey at consultancy and support levels. These two groups were directly involved in I4.0 adoption decision-making and the design of implementation roadmaps. The public sector, research and development sector, and non-governmental organization participants were selected to provide in-depth views on I4.0 adoption with aspects of sustainable development.

Participants were recruited via e-mail, telephone, and LinkedIn. Thirty potential participants were invited, and sixteen agreed to participate. A one-page summary describing the overall study and an informed consent form to be signed by both the potential participant and the researcher formed part of the invitation. The informed consent document stipulated the research overview, expectations from the participant, risks involved, and how the risks would be minimized, as well as the handling and use of the data collected. Participation was voluntary, and all participants were free to withdraw from the research at any time during or after the interview. The study was conducted under the guidelines and clearance from the researchers' institution's ethical clearance process.

Table 2 shows the participants distribution by industry. The manufacturing and digital industries were represented by about two-thirds of the participants, with the rest representing the other selected relevant interested parties. 
Table 2. Participant distribution by industry.

\begin{tabular}{ccc}
\hline Industry & Number of Participants (\%) & Participants ${ }^{\mathbf{1}}$ \\
\hline Manufacturing & $5(31)$ & P3, P4, P8, P9, P16 \\
\hline Digital & $5(31)$ & P5, P11, P12, P13, P14 \\
\hline Research and development & $2(13)$ & P1, P6 \\
\hline Public sector & $3(19)$ & P2, P10, P15 \\
\hline Non-governmental organizations & $1(6)$ & P7 \\
\hline 1 Participants are referred to as P (participant) folowed by an identifying nut
\end{tabular}

${ }^{1}$ Participants are referred to as $\mathrm{P}$ (participant) followed by an identifying number.

Table 3 shows the participant distribution by type of responsibility. Half were at the managerial level, and the rest were selected for their specialist expertise. A technology agreements facilitator, working in the government department responsible for the manufacturing industry and technology adoption, was included for perspectives relating to liaison between the industry and government.

Table 3. Participant distribution by responsibility.

\begin{tabular}{ccc}
\hline Responsibility/Position & Number of Participants (\%) & Participants \\
\hline Management level & $8(50)$ & P1, P3, P4, P5, P8, P10, P12, P15 \\
\hline Specialist/expert level & $7(44)$ & P6, P7, P9, P11, P13, P14, P16 \\
\hline $\begin{array}{c}\text { Other-Technology } \\
\text { agreements facilitator }\end{array}$ & $1(6)$ & P2 \\
\hline
\end{tabular}

\subsection{Data Collection}

To collect a rich dataset and participants' broader views [53], the semi-structured interviews focused on obtaining an understanding of factors influencing sustainable adoption of I4.0 in South African manufacturing. They were conducted face-to-face or by telephone, depending on the participant's preference. All were conducted in English, and no language barrier was encountered. They were audio-recorded, and field notes were taken during the course of the interviews as a first step in ensuring data credibility.

Two standard open-ended questions guided each interview: (a) can South Africa adopt I4.0 in the same way as other countries and please elaborate on your answer? and (b) please discuss the factors that you think inhibit the sustainable adoption of I4.0 in the South African manufacturing industry? The interviews lasted about $45 \mathrm{~min}$ to one hour, depending on the time taken to answer follow-up questions posed to yield in-depth opinions and explanations from participants. The questions were designed to collect data on the nature of the environment in which the manufacturing industry was operating, contextual factors affecting sustainable adoption of I4.0, and strategies to enhance sustainable adoption of I4.0 in the South African manufacturing industry.

\subsection{Data Analysis}

The interview recordings were transcribed verbatim, and the accuracy of the transcriptions was checked by subsequently comparing them with the recording and correcting the final versions as necessary.

Thematic analysis was used to identify patterns and themes in the data. This method provides the means to stay close to the data while presenting a sufficient summary of participants' views [48]. To ensure rigor, the data analysis followed the process of data familiarization, initial codes generation, reviewing of codes, searching for themes, theme review, and theme generation [54,55].

The researchers listened to the audio readings during the transcription process and formulated initial thoughts and ideas. Potentially interesting data segments were highlighted, and patterns of meaning underlined. Transcripts were imported into ATLAS.ti, 
and the researchers carefully read through each script, started to organize the data into meaningful chunks of data [54], and created the initial code lists using open coding in ATLAS.ti [56].

Codes were reviewed by renaming and merging codes while identifying patterns and relationships using links and network functions in ATLAS.ti [56]. This led to the identification of code categories and the generation of descriptive themes. The researchers maintained participants' views in line with the objective of a qualitative descriptive study $[49,52,57]$. The importance of each theme related to the research questions was generated. A summary of the themes, categories, and codes is presented in Table 4, followed by a detailed representation of participants' views. Furthermore, the co-occurrence table tool in ATLAS.ti was used to identify frequencies and determine noticeable overlaps of codes [56]. This was used for exploratory purposes and for identifying codes that required further analysis.

Table 4. Themes, sub-themes, and codes used.

\begin{tabular}{|c|c|c|}
\hline Theme & Sub-Theme & Associated Codes \\
\hline \multirow{4}{*}{$\begin{array}{l}\text { Factors that inhibit I4.0 } \\
\text { adoption in the } \\
\text { South African } \\
\text { manufacturing industry }\end{array}$} & Socioeconomic factors & $\begin{array}{l}\text { Resistance to technology, cultural construct, social structural } \\
\text { inequalities, noticeable youth unemployment, limited access to } \\
\text { information, awareness challenges, I4.0 geared towards } \\
\text { competitiveness, slow pace of adoption. }\end{array}$ \\
\hline & Task environment factors & $\begin{array}{l}\text { Policy constraints, fragmented task environment, lagging industrial } \\
\text { development, exponential rate of change, inadequate innovation } \\
\text { system, international developments and trends, government support. }\end{array}$ \\
\hline & Infrastructure factors & $\begin{array}{l}\text { Equipment not supporting I4.0 requirements, inadequate ICT } \\
\text { infrastructure, limited access to I4.0 technologies, limited access to } \\
\text { reliable electricity supply, limited availability of advanced technologies. }\end{array}$ \\
\hline & Human capital factors & $\begin{array}{l}\text { Critical skills shortage, inadequate alignment between skills } \\
\text { development and skills requirements, skills migration, potential } \\
\text { negative impact on low-skilled and semi-skilled jobs. }\end{array}$ \\
\hline $\begin{array}{l}\text { Strategies to promote I } 4.0 \\
\text { adoption in the } \\
\text { South African } \\
\text { manufacturing industry }\end{array}$ & & $\begin{array}{l}\text { Understand context and apply relevant technologies, strengthen policy } \\
\text { and regulatory space, overhaul education system, create I4.0 awareness, } \\
\text { invest in I4.0 infrastructure, ensure collaboration between partners, } \\
\text { enhance international relationships, focus on primary manufacturing, } \\
\text { select technologies that enhance human capability and productivity. }\end{array}$ \\
\hline
\end{tabular}

\section{Findings}

From our analysis of the 16 interviews, two key themes emerged: factors that inhibit I4.0 adoption and strategies to promote I4.0 adoption in the South African manufacturing industry. Table 4 presents an overview of these themes, associated sub-themes, and the codes that were generated. These are further analyzed in Section 4.1 to Section 4.3. Though it is not a standard practice in a qualitative study, we included graphs that provide an overview of the prevalence of each inhibitor by the number of participants.

\subsection{Sustainable Adoption of Industry 4.0 Inhibiting Factors}

Factors that, according to our participants, inhibit sustainable adoption of I4.0 are grouped into four sub-themes: socioeconomic factors, task environment factors, infrastructure factors, and human capital factors.

\subsubsection{Socioeconomic Factors}

All of the participants agreed that socioeconomic factors significantly inhibit the sustainable adoption of I4.0 in the South African manufacturing industry. Figure 1 shows the number of participants who highlighted the presence of each socioeconomic inhibiting factor. 
Participants from the manufacturing industry (P3), digital industry (P12), research and development (P1, P6), public sector (P2, P10), and NGO (P7) saw resistance to I4.0 technologies as a key barrier to adoption, and one in particular emphasized that such resistance was strengthened by labor unions' concern that I4.0 could potentially reduce or even eliminate low-skilled and semi-skilled jobs:

"The other aspect from a social point of view that may be a barrier is [the] acceptance of the technologies. If you look at what the labor unions are talking about at the moment, they are more worried about job losses." (P1)

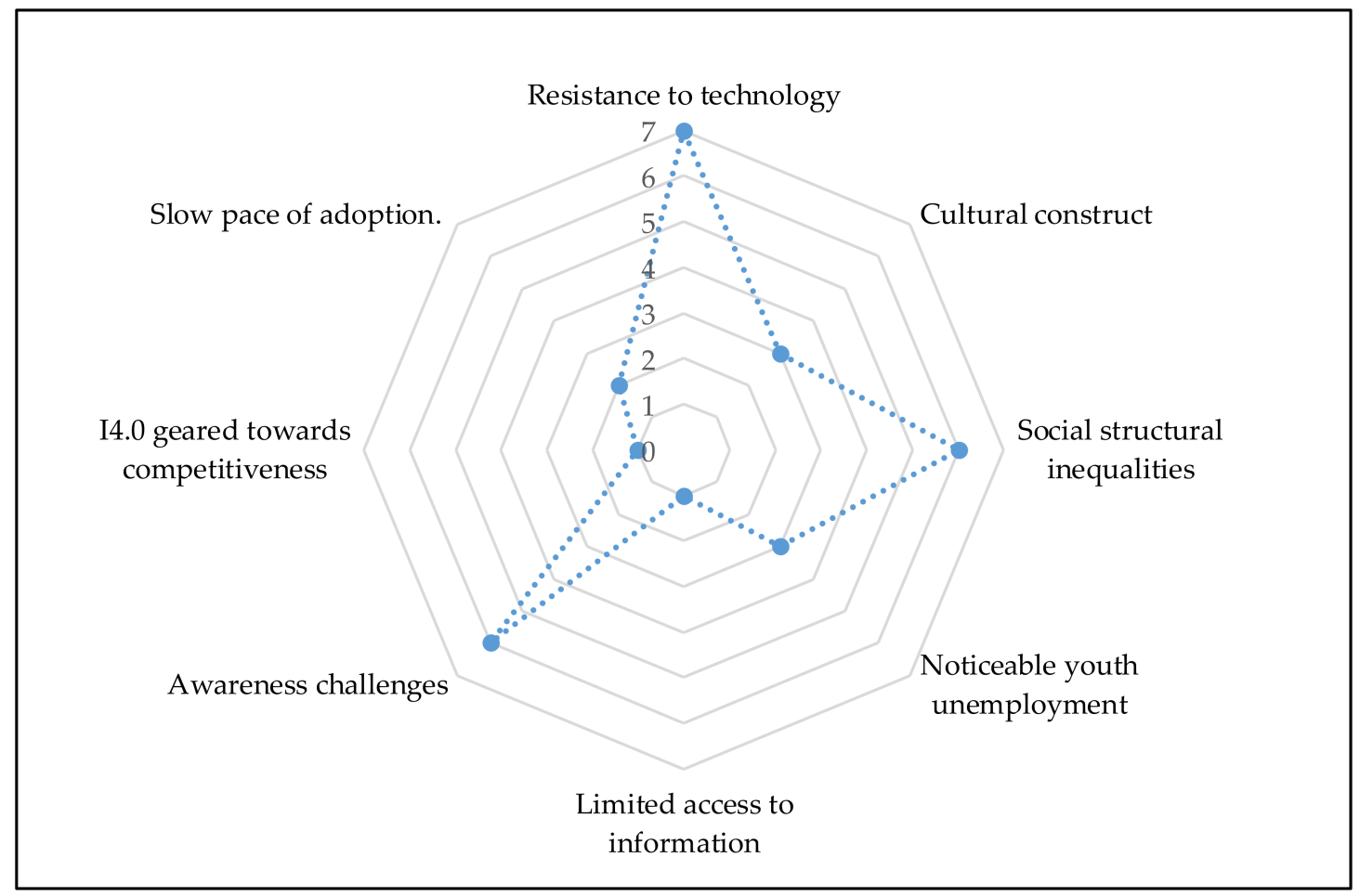

Figure 1. Socioeconomic inhibiting factors versus the number of participants.

There was also agreement from participants at management (P5) and specialist/expert (P9, P13) levels, as well as from the technology agreements facilitator, that youth unemployment deriving from their lack of basic skills greatly adds to the social-economic inhibitors to I4.0 adoption:

"This country has problems with unemployment among young people, who come out of school and matriculation without a good education and even a very poor ability to read." (P13)

Social structural inequalities and the "the extent to which the society is wired" (P5) in South Africa additionally hinder sustainable adoption of I4.0, as pointed out by six of the participants, at management (P1, P3, P5, P10) and specialist/expert (P13) levels. They stressed the fact that I4.0 adoption in the country must focus on solving both competitiveness and equality challenges:

“. . . I4.0 in places like Germany is about economic competitiveness. It's about making firms and sectors and the whole Germany economy more competitive in the global landscape ... I4.0 in South Africa can't only be about competitiveness, it can't only be about firms investing in high tech and upgrading their tech and make more money. It can't just be about competing; it has also to be in some sense competing while addressing the serious issue of inequality in this country." (P10) 
Participants at the management level (P3-P5, P12) and specialist/expert level (P6, P7) highlighted the lack of awareness or understanding about I4.0, its impact, and how it can be adopted in their organizations, and saw this as a factor that can restrict successful adoption:

"I think it's number one, unawareness, overall unawareness ... So people they hear that there is I4.0, but they don't know where to start, they don't know how [they can go about] implementing it." (P4)

\subsubsection{Task Environment Factors}

Figure 2 presents the task environment factors versus the number of participants who pointed to them as factors that inhibit sustainable adoption of I4.0 in the South African manufacturing industry.

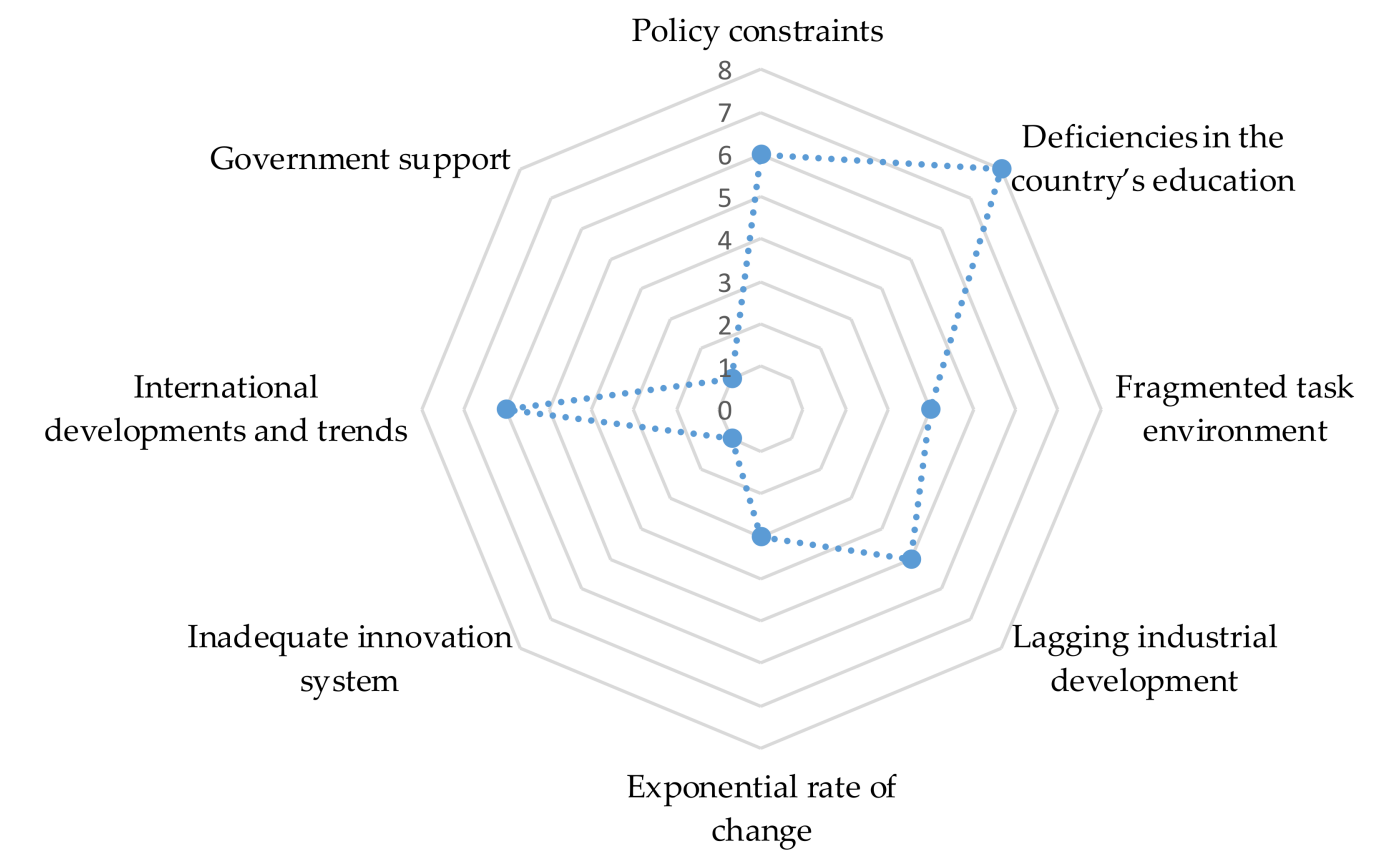

Figure 2. Task environment inhibiting factors versus the number of participants.

Participants from the manufacturing industry (P4, P8), public sector (P2), research and development (P6), and NGOs (P7) were concerned that policy and regulations in South Africa were not supportive of large-scale I4.0 adoption. Furthermore, the country's policy framework, as observed by a public-sector participant, does not support swift adjustment to exponential technological advancements:

"We do not have government policies in place that will enable [the] business to easily apply all the I4.0 stuff or elements." (P4)

“... we haven't achieved full readiness, so we need to use a mixture of policies to make sure that we adjust, policies that speak to our economic competitiveness in the manufacturing sector . . . microeconomic policies, as well [as] policies around education sector . . . regulations around the digital space are not yet completed, which inhibits I4.0 being rolled out on massive scale in a way that everybody who wants to play in this space can do." (P2)

However, nobody representing the digital industry had similar concerns, perhaps because, as another public-sector participant pointed out, there was currently considerable 
policy discussion on facilitating I4.0 in the country, even as he acknowledged the challenges in respect to policy and regulation:

"The public sector in terms of policy I think it is getting uptake and I think there are a lot of policy discussions happening right now about how public sector can facilitate a link towards I4.0." (P10)

Participants from all of the represented groups agreed that the deficiencies in the country's education system have a significant negative impact on sustainable I4.0 adoption. They described the system as being characterized by poor-quality teaching and learning, misalignment in the development of skills required by industry, and underperformance in tertiary education throughput:

"There is a huge obligation of the government departments that reports within the government, like education, that they must pull up their socks and make sure the quality of qualifications that comes out of matric is up to standard. How can you expect somebody that can only know $33 \%$ of the subject matter to be proficient? There is $67 \%$ that he does not know that he could not give an answer to or give the correct answer to. So how is that person equipped for the big world out there to come and render a service?" (P4)

The South African manufacturing industry is lagging in terms of industrial revolutions, with some companies still struggling with the second industrial revolution, as pointed out by participants at the management (P1, P4, P5, P8) and specialist/expert (P7) levels:

"I think that the current system is so flawed in all its ways. I mean we [are] talking the second industrial revolution not even third. It almost needs a complete revamp from the future requirement point of view as opposed to reengineering the current system to support the fourth industrial revolution environment." (P7)

There was also agreement from participants at the management (P3, P4, P5) and specialist/expert (P6, P7) levels, as well as from the technology agreements facilitator (P2), that a significant number of manufacturing organizations in the country react to the trend in technological advancement rather than strategically respond to it.

\subsubsection{Infrastructure Factors}

The number of participants who pointed out each infrastructure factor that inhibits sustainable adoption of I4.0 in the South African manufacturing industry is presented in Figure 3.

The participants in the manufacturing industry (P3, P4, P8, P9), digital industry (P5, $\mathrm{P} 11, \mathrm{P} 12)$, research and development (P10), and public sector (P2, P10) categories all agreed that the country faced considerable infrastructural challenges, including those related to information and communication technology (ICT):

"We do not necessarily have the ICT infrastructure to facilitate the establishment of cyber-physical systems and IoT [Internet of Things], which are the pillars in I4.0." (P10)

Participants at the management level (P1, P4) and specialist/expert level (P6, P9, P11) concurred that access to advanced technologies is a barrier to inclusive participation in I4.0. "Technologies are expensive" (P1), and "SMEs will not be able to afford" (P4) the necessary I4.0 supporting infrastructure.

The technology agreements facilitator highlighted a lack of reliable electricity supply as a major obstacle to the successful adoption of I4.0:

". . . lack of access to reliable electricity, which is a basic infrastructure that we need to run the devices and if you don't have access to alternative source of energy and [you] rely on the public grid for electricity or energy you are obviously going to be limited as you know, recently with blackouts we have been experiencing." (P2) 


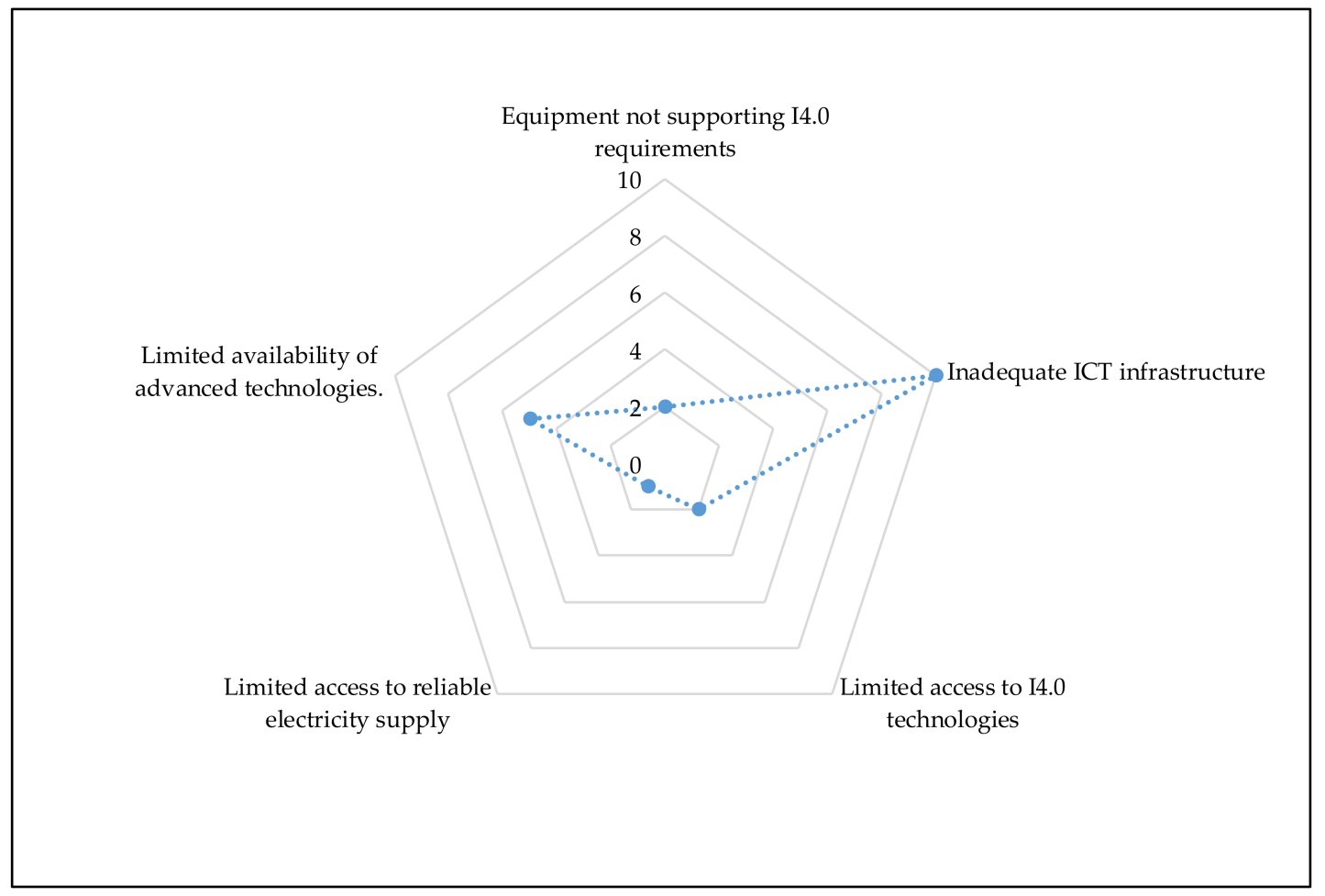

Figure 3. Infrastructure inhibiting factors versus the number of participants.

\subsubsection{Human Capital Factors}

Figure 4 highlights the human capital factors versus the number of participants who pointed to them as factors that inhibit sustainable adoption of I4.0 in the South African manufacturing industry.

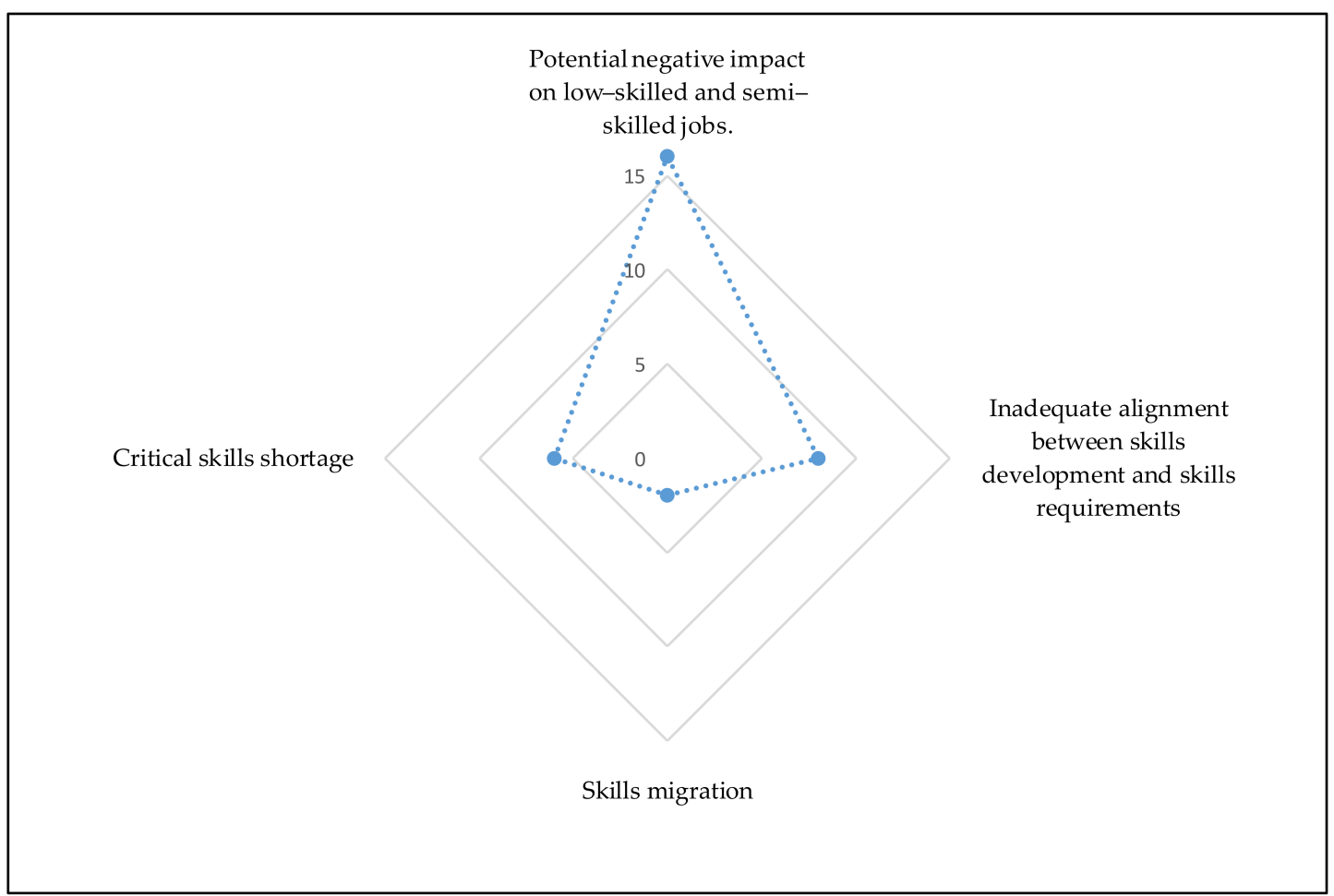

Figure 4. Human capital inhibiting factors versus the number of participants. 
Participants at the management level (P1, P3, P4) and specialist/expert level (P6, P11, P13) believed that specialized skills required to participate in I4.0 were lacking due to insufficient development of such skills:

"I think the whole skills issue is one of the biggest problems that this country faces in trying to get itself ready for the I4.0 . . But also to produce people with specialized skills required to work in I4.0. That for me is going to be one of the biggest challenges this country faces." (P13)

There was agreement from participants in the manufacturing industry (P8, P9), digital industry (P5, P12, P13), research and development (P6), public sector (P10), and NGO (P7) about the mismatch between the skills required by the industry and I4.0 and the skills being produced by the education system, which results in unemployment or underemployment:

". . . the current system is currently defective because about $70 \%$ of South Africans ultimately either become unemployed or underemployed. So why do you train people for unemployment?" (P7)

"The education needs to prepare us for I4.0 because at the moment, I feel and I think we are preparing our students and our people for the second industrial revolution, which is the production line type of thinking . . . whereby you just go to school, get good grade, and go work somewhere else, you know. But I4.0 needs a shift, needs a paradigm shift that talks to the mindset how we do things." (P9)

All of the participants agreed that 44.0 could potentially reduce or even eliminate certain low-skilled and semi-skilled jobs, since technologies in I4.0 are structured around automation, artificial intelligence, and competitiveness; this creates challenges for the country's manufacturing industry, which currently employs a significant number of people in such jobs:

"It's a big challenge because I4.0 per say is geared towards competitiveness . . . none of that is about inclusiveness. And I personally don't see a clear path with making that inclusive because ultimately I4.0 it's about competitiveness that is driven by automation, and if you are automating there are chances of employing fewer people. You might be employing fewer low-skilled people. You might be paying more money to the high-skilled people. So here is the dynamics of I4.0 that could be seen to run against the principle of inclusiveness." (P10)

"We have the debates around artificial intelligence, machine learning, robotics being a threat to low-skilled and semi-skilled jobs in our manufacturing industry. So the question is what kind of policy do we assume to ensure that we secure rather than bring instability to those sectors, what alternative source of work do we have [for] them." (P2)

Participants from the manufacturing industry (P8) and digital industry (P11) believed that the migration of people with specialized skills looking for greener pastures in other countries adds to the skills challenge faced in South Africa.

"South Africans do great things in other countries, especially overseas, you know.

We can replicate the same effort in our economy." (P8)

\subsection{Strategies to Promote I4.0 Adoption}

The number of participants who pointed out each strategy to promote I4.0 adoption in the South African manufacturing industry is presented in Figure 5.

All of the participants agreed that understanding the country's contextual operating environment could assist in adopting specific I4.0 technologies that would help to solve its specific challenges:

"We have to look into South African context and say ... what are the kind of the problems we want to solve? What is important to South Africa? Because if you look at things like autonomous drivers, yes, it is important to the problems of 
those developed countries, but is it really important here in South Africa? We have got other big challenges that we can solve with I4.0." (P11)

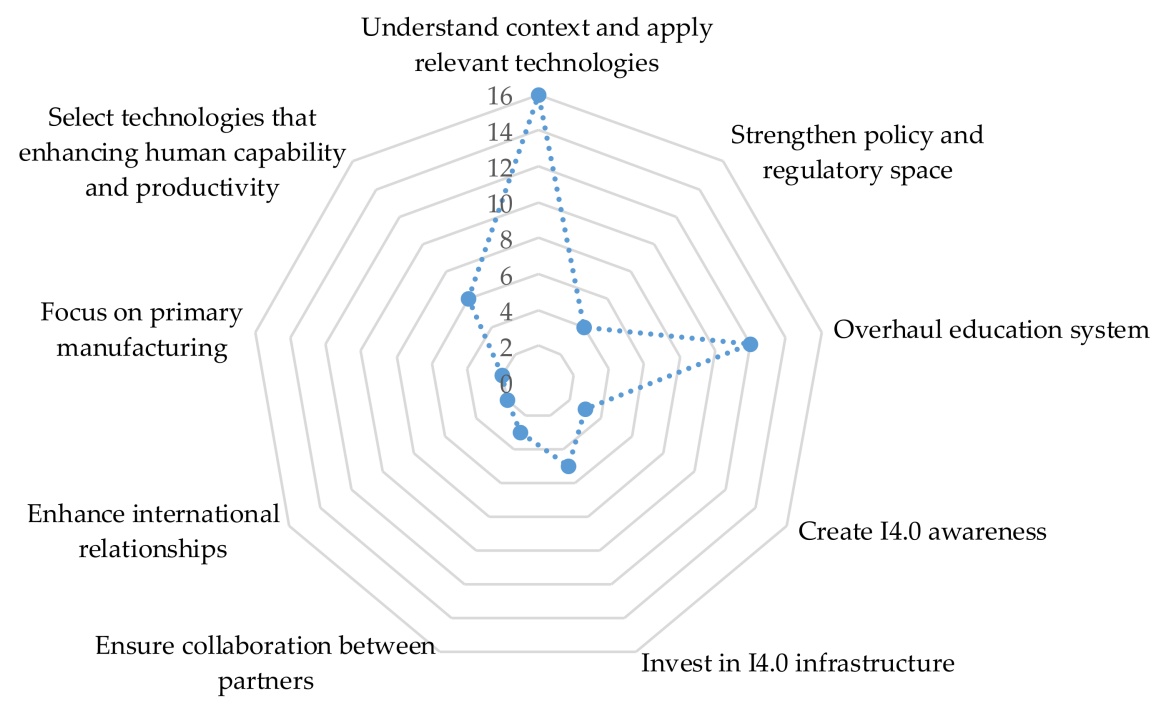

Figure 5. Strategies to promote I4.0 adoption versus the number of participants.

Participants at the management (P1, P4) and specialist/expert (P6, P7, P9, P11) levels believed that manufacturing companies could select I4.0 technologies that augment and enhance human capability and create and enhance jobs as a strategy to promote sustainable adoption of I4.0 in the country:

"So instead of full-blown automation, we need to adopt solutions that do not have adverse impact on the employment scenario because that would then have impact on the social-political kind of human activities." (P11)

"So there is really an opportunity to make it [I4.0 technology] relevant for those people who have been stuck in this element of low-paying jobs and menial labor, and one can make those kind of workers as better and easier and more fun experiences. It really goes down to, it makes the job more interesting if you have wonderful high technologies that can aid you and save you time and save you effort." (P6)

Participants from the manufacturing industry (P3, P4), digital industry (P13), and research and development $(\mathrm{P} 1, \mathrm{P} 6)$ thought that various stakeholders' uncertainty about the impact of adopting I4.0 could be addressed by making people aware of "what is I4.0 and what elements can be adopted" (P4) without taking away jobs:

"I think we can support adoption of I4.0 first and foremost by educating people that it's not going to take away jobs. There is a tremendous fear in the government and among the labor unions in South Africa that I4.0 means job losses, job cuts, people on the streets, civil unrest." (P1)

All of the participant categories emphasized the responsibility of the government in creating the policy and regulatory environment that promotes the manufacturing industry to do business and thrive in I4.0:

"So the government must create an environment in which businesses can easily apply and thrive with all the aspect of Industry 4.0." (P4) 
Participants at the management (P8, P10, P12) and specialist/expert level (P7, P9, P11, P13) further highlighted the value of revamping the education system to respond to current and future skills requirements as a strategy to support the sustainable adoption of I4.0.

A specialist/expert in the digital industry (P13) emphasized the need for government incentives to companies that are sustainably adopting I4.0 initiatives to stimulate similar investments in the manufacturing industry:

"South African manufacturing industry can leverage I4.0 if there [is] a way that maybe [the] government can provide incentives in some way for companies to invest in the latest technologies. Is there some way that they could reduce their corporate tax they pay . . . because they have invested a certain amount of money in improving their systems, their processes, the way they do things?" (P13)

Managers (P1, P8) and specialist/expert participants (P6, P7, P13) were optimistic that if companies focused on investing in I4.0 technologies, this would promote achieving successful adoption of I4.0 in the country. They emphasized the importance of understanding the difference between investing in the third industrial revolution and fourth industrial revolution technologies:

". . . if we do these investments, we have to invest not for the third industrial revolution, but for the fourth [industrial revolution]. So in other words if [we] go and invest and every company invest, we need to make sure that whatever we create in terms of infrastructure is geared towards the fourth industrial revolution. So I think consider the question what is the difference between investing in third industrial revolution as with the fourth [industrial revolution]. What does that mean?" (P7)

Participants at the management level (P1, P4, P10) and specialist/expert level (P14) suggested that collaboration and strategic partnerships between companies and groups within the country and abroad would promote sustainable adoption of I4.0 and attract international interaction and investment:

"Strategic partnership. So what I mean by that is companies in South Africa who are working in a specific area like manufacturing in a particular way with particular products within the industry, can they think to have strategic partnership with companies in other countries oversees, where they will benefit from what those companies have learnt and the way those companies overseas have done things. In return, help those overseas companies also doing more business in South Africa. So it works both ways. So if there are partnerships that South African companies can have with maybe a similar or complementary technology company in another country where each can support each other and win business with each other's markets to grow their business." (P13)

\subsection{Relationships Diagram of Inhibitors to Sustainble Adoption of I4.0}

The inhibitors of sustainable adoption of I4.0 in the South African manufacturing industry were further analyzed to identify their relationships using the links function in ATLAS.ti [56]. Three major ATLAS.ti relationships were employed in the analysis: 'is part of', 'is associated with', and 'is cause of'. Furthermore, 'will intensify', a customized relationship, was used to link other codes. Figure 6 illustrates the established relationships between the theme factors that inhibit sustainable I4.0 adoption (green) and the four sub-themes (blue) with their associated codes (red).

A significant number of inhibitors were identified to be linked with deficiencies in the education system: noticeable youth unemployment, critical skills shortage, inadequate alignment between skills development and skills requirements, and awareness challenges. This will all cause the slow pace of adoption of I4.0 technologies in the manufacturing industry.

Slow pace to the adoption of I4.0 was identified to be caused by the resistance to technology and the cultural constructs within the country. Furthermore, it was associated with the policy environment that does not support quick changes in requirements in the industry. 


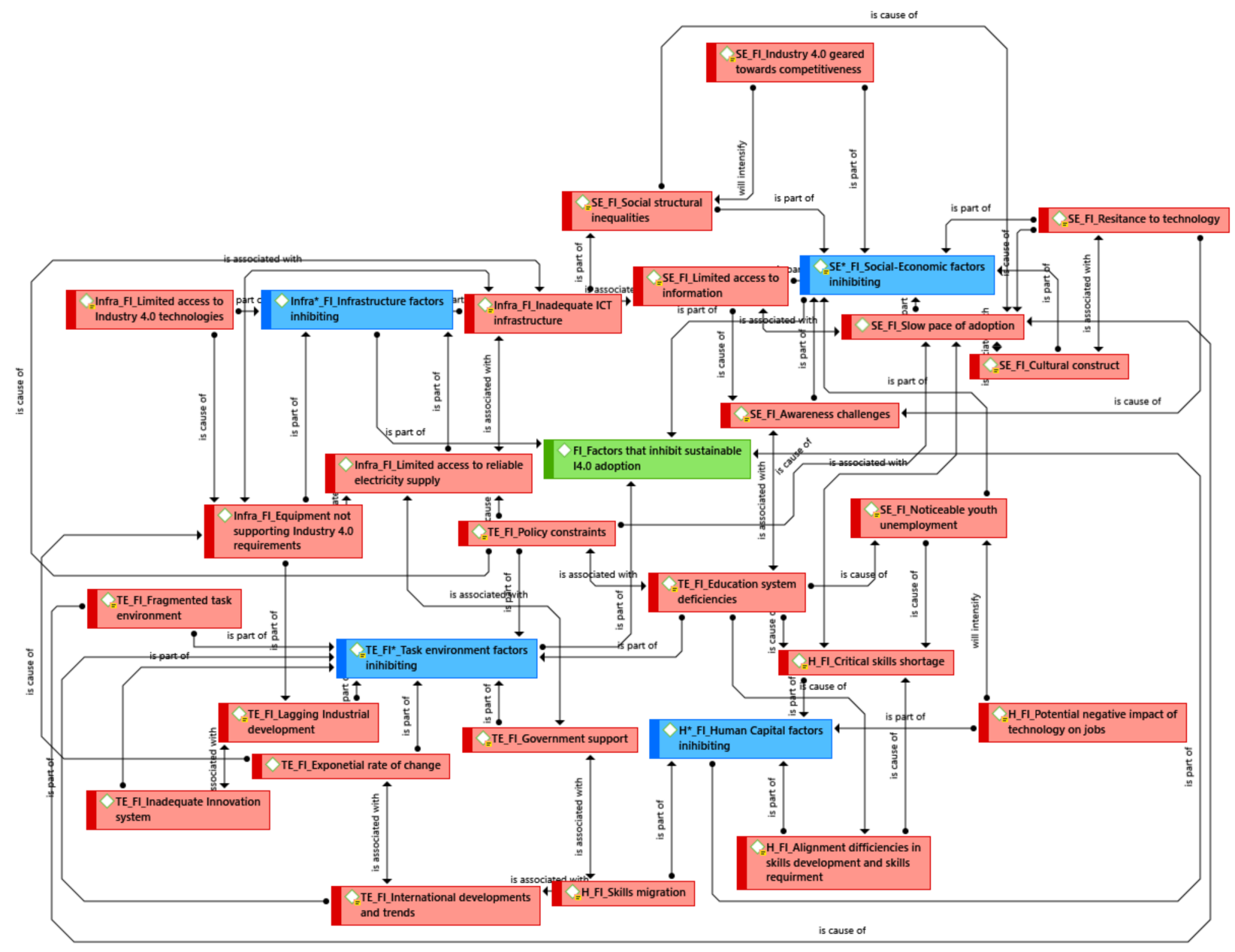

Figure 6. Relationships diagram of inhibitors to sustainable adoption of I4.0.

Policy constraints were linked with causing inhibitors, such as inadequate ICT infrastructure, limited access to reliable electricity, and deficiencies in the education system.

The potential negative impact of technology on jobs was linked with the potential to strengthen noticeable youth unemployment, while the perception that I4.0 is geared towards competitiveness could strengthen social structural inequalities in the country.

The inhibitor of equipment not supporting I4.0 requirements was identified to be caused by the exponential rate of change of technologies and limited access to I4.0 technologies. This inhibitor is associated with limited access to a reliable electricity supply and inadequate ICT infrastructure. Furthermore, equipment not supporting I4.0 requirements is considered as part of lagging industrial developments.

\section{Discussion and Recommendations}

\subsection{Discussion}

The current study explored the factors that inhibit sustainable adoption of I4.0 in the South African manufacturing industry. Our research utilized the views of management and experts in the manufacturing and related supporting industries, who pointed out inhibitors specific to the country, including social structural inequalities, resistance to technology, noticeable youth unemployment, a fragmented task environment, and deficiencies in the education system. They also suggested strategies that can enhance sustainable I4.0 adoption in the industry, which relate to South Africa, but that could also apply to other countries in the region.

Because I4.0 adoption could potentially reduce or even remove certain low-skilled and semi-skilled jobs, which stakeholders such as labor unions fear, mitigating action 
would need to be taken to avoid jeopardizing the achievement of SDGs relating to equality and inclusiveness. In their inter-country comparative study, for example, Raj et al. [10] highlighted inequalities as an inhibitor to the possible results and benefits of I4.0 adoption. Our findings, therefore, support a focus on the skilling and re-skilling of employees in organizations as a way to provide for continuing employability of the existing workforce as I4.0 is adopted. Furthermore, careful selection of technologies that drive inclusiveness and support employment creation would be needed.

Our participants observed that South African manufacturing operates in a fragmented task environment, which could inhibit efforts to establish a unified direction in adopting I4.0. Furthermore, the regulatory and policy framework was not seen to support largescale adoption of I4.0, and was insufficiently able to address rapid changes related to I4.0 technologies. Our findings suggest that the South African government could learn and adapt for its own purposes lessons from countries such as Germany, whose government supported the 2020 High-Tech Strategy that led to the establishment and implementation of I4.0 [51,52].

Our findings also accentuate the infrastructure challenges-notably ICT-to I4.0 adoption. These are not unique to South Africa [10], but are worsened in this country and others in the region, where basic infrastructural support, such as a reliable electricity supply, is lacking.

Our findings indicated human capital challenges as a further significant inhibitor of sustainable adoption of I4.0 in manufacturing, and are consistent with other studies $[9,10,13,31,35,58]$ that reveal workforce and skills challenges as barriers to such adoption. Although workforce challenges are a common theme in developed as well as developing countries, their causes are often specific to the type of country. For example, developed countries face the challenge of aging populations and justifying their strategy of adopting advance robotics and automation related to I4.0 as a solution [9,11]. In South African manufacturing, by contrast, there are many young job-seekers, but too many of them lack the relevant I4.0 skills because of deficiencies in the education system and misalignment between the industry's skill requirements and actual skill development. The implication, therefore, is that I4.0 solutions in South Africa must focus on enhancing and improving human capacity-as well as the education and skills development system itself-rather than replacing the workforce.

In addition to gaining an understanding of inhibitors to I4.0, the present study revealed potential strategies to promote sustainable adoption of I4.0 in the South African manufacturing industry. The strategies pointed out in this study could assist investors to focus on issues that will increase their chance of acceptance and success in the country and the region.

The findings of this study revealed that I4.0 adoption in the South African manufacturing industry should consider balancing competitiveness aspects and meeting the country's NDP and SDG aspects of inclusiveness and equality. Prevailing socioeconomic challenges, such as social structural inequalities and noticeable youth unemployment, necessitate the manufacturing industry and its supporting industries to innovate I4.0 technologies for successful adoption.

Furthermore, policymakers in the country should develop policies and regulations that support technology acceptance by various stakeholders, which include the workforce, labor unions, and investors. Targeted regulations and policy that require attention could include ICT, skills development, education, and trade and industry policies.

The study suggests that successful adoption of I4.0 significantly depends on people as well as technology. It is people in combination with technology that can change and improve situations. A shortage of I4.0 skill requirements was identified as a global challenge $[5,10]$, and competition for people with relevant skills could intensify. Therefore, South Africa's manufacturing industry must intensify skills development, as well as skills retention, as linked strategies to mitigate skills shortage and skills loss. 


\subsection{Study Limitations and Future Studies}

Although these findings have contributed to our understanding of management and experts' perspectives on the adoption of I4.0, we acknowledge that there are limitations to the study. It is not the first to explore factors that inhibit I4.0 adoption in the manufacturing industry $[2,4,5,9-13,25,26]$, although it is the first to address the issue in the specific country context of South Africa. The small sample size could be regarded as a limitation, although it fits well into the research design and the purpose of the study. Thus, the findings are not generalizable owing to the small sample size and the subjectivity of participants' opinions. Nevertheless, the points they raised offer useful direction for further, broader investigations of specific inhibitors to sustainable I4.0 adoption and strategies for overcoming them, not only in South Africa, but also in the developing countries in the same region.

The research design and methodology in this study was limited to qualitative data. This restricted us only to apply qualitative data analysis techniques, and thus the inhibitors could not be ranked in terms of severity. We, therefore, recommend future studies that could use both qualitative and quantitative methods and apply techniques, such as the analytical hierarchy process (AHP) and Delphi technique, for further analysis of the factors that inhibit sustainable adoption of I4.0 in the manufacturing industry.

This study also opens doors for future research into factors that inhibit I4.0 adoption within specific manufacturing industry sectors where its impact and opportunities could vary.

\subsection{Recommendations}

Our findings suggest that deficiencies in the education system are significantly linked to other inhibitors, and addressing these could contribute to mitigating factors that are inhibiting sustainable adoption of I4.0. Fixing the deficiency in the education system, coupled with organizations prioritizing up-skilling and re-skilling of employees, could provide solutions to inhibitors, such as the noticeable youth unemployment, critical skills shortage, inadequate alignment between skills development and skills requirements, and awareness challenges. Thus, various stakeholders, including the government departments, such as basic education, higher education, and training, and the department of science and technology, must collaborate with other stakeholders, such as the industry and trade unions, in addressing the deficiencies thereof.

Policy constraints were also linked to a noticeable number of inhibitors, such as inadequate ICT infrastructure, limited access to reliable electricity, and deficiencies in the education system. Since changes in technological development are exponential, it is recommended that the policy framework in the country must be flexible and quick to adopt all necessary changes that foster sustainable development. The suggested targeted regulations and policies that will have a significant impact and require attention could include regulations around ICT, skills development, education, and trade and industry policies.

It is further recommended that the manufacturing industry in the country must not adopt I4.0 for the sake of following global trends. Instead, decision-makers must seek to understand the contextual country requirements and apply relevant technologies that support such. This could include selecting technologies that enhance human capabilities, thus minimizing the possible negative impact of I4.0 technologies on semi-skilled and low-skilled employees.

\section{Conclusions}

The study aimed to explore factors that inhibit sustainable adoption of I4.0 in the developing country context of the South African manufacturing industry. The present small-scale study offered us the opportunity to gather views from individuals whose work was relevant to I4.0 adoption in the country's manufacturing industry. Although the focus was on factors that inhibit I4.0 adoption, strategies to promote it emerged during data analysis as a strong second theme. These included understanding the context and application of relevant technologies; strengthening the policy and regulatory space; 
overhauling the education system; and selecting technologies that enhance human capability and productivity. The findings suggest that successful adoption of I4.0 goes beyond the development of technological capabilities, and needs to also take into consideration aspects of social-economic sustainability. In the context of South African manufacturing, sustainable adoption entails balancing competitiveness with inclusivity in ways that help to achieve the goals embedded in the country's NDP and the UN's SDGs, and that move the industry—and the country—towards stronger economic growth and quality of life for all.

Author Contributions: W.M. was responsible for data collection, data analysis, and preparing the manuscript-the work is based on his PhD studies. L.v.D. and R.C. supervised the study. All authors discussed the results and contributed to the final manuscript. All authors have read and agreed to the published version of the manuscript.

Funding: This research received no external funding.

Institutional Review Board Statement: The study was conducted according to the guidelines and approved by the North-West University Engineering Research Ethics Committee (NWU-ENGREC)—Approval number and date (NWU-00284-19-A1, 23 August 2019).

Informed Consent Statement: Informed consent was obtained from all subjects involved in the study.

Data Availability Statement: The data presented in this study are available on request from the corresponding author. The data are not publicly available due to consent restrictions provided by participants.

Conflicts of Interest: The authors declare no conflict of interest.

\section{References}

1. Hermann, M.; Pentek, T.; Otto, B. Design principles for Industrie 4.0 scenarios. In Proceedings of the 49th Hawaii International Conference on System Sciences (HICSS), Koloa, HI, USA, 5-8 June 2016; pp. 3928-3937. [CrossRef]

2. Müller, J.M. Assessing the barriers to Industry 4.0 implementation from a workers' perspective. IFAC-PapersOnLine 2019, 52, 2189-2194. [CrossRef]

3. Nwaiwu, F.; Duduci, M.; Chromjakova, F.; Otekhile, C.F. Industry 4.0 concepts within the Czech SME manufacturing sector: An empirical assessment of critical success factors. Bus. Theory Pract. 2020, 21, 58-70. [CrossRef]

4. Luthra, S.; Kumar, A.; Zavadskas, E.K.; Mangla, S.K.; Garza-Reyes, J.A. Industry 4.0 as an enabler of sustainability diffusion in supply chain: An analysis of influential strength of drivers in an emerging economy. Int. J. Prod. Res. 2020, 58, 1505-1521. [CrossRef]

5. Kumar, S.; Suhaib, M.; Asjad, M. Analyzing the barriers to industry 4.0 through best-worst method. Int. J. Perform. Eng. 2020, 16, 27-36. [CrossRef]

6. Van Niekerk, A.J. Inclusive Economic Sustainability: SDGs and Global Inequality. Sustainability 2020, 12, 5427. [CrossRef]

7. United Nations. Transforming Our World: The 2030 Agenda for Sustainable Development. Available online: \protect $\backslash u n h b o x \backslash$ voidb@x \hbox\{https:// s sustainabledevelopment.un.org/content/documents/21252030\%20Agenda\%20for\%20Sustainable\% 20Development\%20web.pdf (accessed on 20 March 2020).

8. Sanchez, D.O.M. Sustainable Development Challenges and Risks of Industry 4.0: A literature review. In Proceedings of the 2019 Global IoT Summit (GIoTS), Aarhus, Denmark, 17-21 June 2019; pp. 1-6. [CrossRef]

9. Horváth, D.; Szabó, R.Z. Driving forces and barriers of Industry 4.0: Do multinational and small and medium-sized companies have equal opportunities? Technol. Forecast. Soc. Chang. 2019, 146, 119-132. [CrossRef]

10. Raj, A.; Dwivedi, G.; Sharma, A.; de Sousa Jabbour, A.B.L.; Rajak, S. Barriers to the Adoption of Industry 4.0 Technologies in the Manufacturing Sector: An Inter-Country Comparative Perspective. Int. J. Prod. Econ. 2019, 224, 107546. [CrossRef]

11. Türkeș, M.C.; Oncioiu, I.; Aslam, H.D.; Marin-Pantelescu, A.; Topor, D.I.; Căpușneanu, S. Drivers and Barriers in Using Industry 4.0: A Perspective of SMEs in Romania. Processes 2019, 7, 153. [CrossRef]

12. Müller, J.M.; Kiel, D.; Voigt, K.I. What drives the implementation of Industry 4.0? The role of opportunities and challenges in the context of sustainability. Sustainability 2018, 10, 247. [CrossRef]

13. Kamble, S.S.; Gunasekaran, A.; Sharma, R. Analysis of the driving and dependence power of barriers to adopt Industry 4.0 in Indian manufacturing industry. Comput. Ind. 2018, 101, 107-119. [CrossRef]

14. Prather-Kinsey, J. Developing countries converging with developed-country accounting standards: Evidence from South Africa and Mexico. Int. J. Account. 2006, 41, 141-162. [CrossRef]

15. Republic of South Africa. Sustainable Development Goals in South Africa. Available online: https://sustainabledevelopment.un. org/content/documents/24474SA_VNR_Presentation__HLPF_17_July_2019._copy.pdf (accessed on 17 March 2020).

16. MerSETA. Sector Skills Plan Update 2019/2020. Available online: http://www.merseta.org.za/Announcements\%20Docs/ merSETA\%20Sector\%20Skills\%20Plan\%202019-2020.pdf (accessed on 20 April 2020). 
17. Oesterreich, T.D.; Teuteberg, F. Understanding the implications of digitisation and automation in the context of Industry 4.0: A triangulation approach and elements of a research agenda for the construction industry. Comput. Ind. 2016, 83, 121-139. [CrossRef]

18. Plattform Industrie 4.0. Industrie 4.0-What Is It? Available online: https://www.plattform-i40.de/PI40/Navigation/EN/ Industrie40/WhatIsIndustrie40/what-is-industrie40.html (accessed on 23 May 2019).

19. Plattform Industrie 4.0. 2030 Vision for Industrie 4.0. Available online: https:/ /www.plattform-i40.de/PI40/Navigation/EN/ Industrie40/Vision/vision.html (accessed on 23 May 2019).

20. Letaba, T.; Pretorius, M.W.; Pretorius, L. Innovation profile from the perspective of technology roadmapping practitioners in South Africa. S. Afr. J. Ind. Eng. 2018, 29, 171-183. [CrossRef]

21. Mueti, N.E.; Mulongo, N.Y.; Kholopane, P.A. A theoretical analysis of industrial 4.0 in the South African SMMEs. In Proceedings of the International Conference on Industrial Engineering and Operations Management (IEOM), Pretoria, South Africa, 29 October-1 November 2018; pp. 1651-1663.

22. Republic of South Africa. National Development Plan-2030 Executive Summary. Available online: https://www.gov.za/issues / national-development-plan-2030 (accessed on 27 February 2019).

23. Republic of South Africa. Understanding the Root Causes of Unemployment. Available online: https://www.gcis.gov.za/ content/resourcecentre/newsletters/insight/issue13 (accessed on 1 April 2019).

24. Republic of South Africa. Sustainable Development Goals: Country Report 2019. Available online: http:/ /www.statssa.gov.za/ MDG/SDGs_Country_Report_2019_South_Africa.pdf (accessed on 27 June 2020).

25. Stentoft, J.; Adsbøll Wickstrøm, K.; Philipsen, K.; Haug, A. Drivers and barriers for Industry 4.0 readiness and practice: Empirical evidence from small and medium-sized manufacturers. Prod. Plan. Control 2020, 1-18. [CrossRef]

26. Prause, M. Challenges of Industry 4.0 technology adoption for SMEs: The case of Japan. Sustainability 2019, 11, 5807. [CrossRef]

27. Dhanpat, N.; Buthelezi, Z.P.; Joe, M.R.; Maphela, T.V.; Shongwe, N. Industry 4.0: The role of human resource professionals. S. Afr. J. Hum. Resour. Manag. 2020, 18, 1-11. [CrossRef]

28. Botha, A.P. Rapidly arriving futures: Future readiness for industry 4.0. S. Afr. J. Ind. Eng. 2018, 29, 148-160. [CrossRef]

29. Dewa, M.T.; Van der Merwe, A.F.; Matope, S. A decision-making framework for implementing digitalisation in the South African tooling industry. S. Afr. J. Ind. Eng. 2018, 29, 245-262. [CrossRef]

30. Maasz, G.J.; Darwish, H. Towards an initiative-based industry 4.0 maturity improvement process: Master drilling as a case study. S. Afr. J. Ind. Eng. 2018, 29, 92-100. [CrossRef]

31. Maisiri, W.; Darwish, H.; van Dyk, L. An investigation of Industry 4.0 skills requirements. S. Afr. J. Ind. Eng. 2019, 30, 90-105. [CrossRef]

32. Fu, Y.; Kok, R.A.W.; Dankbaar, B.; Ligthart, P.E.M.; van Riel, A.C.R. Factors affecting sustainable process technology adoption: A systematic literature review. J. Clean. Prod. 2018, 205, 226-251. [CrossRef]

33. Kang, H.S.; Lee, J.Y.; Choi, S.; Kim, H.; Park, J.H.; Son, J.Y.; Kim, B.H.; Do Noh, S. Smart manufacturing: Past research, present findings, and future directions. Int. J. Precis. Eng. Manuf. Green Technol. 2016, 3, 111-128. [CrossRef]

34. Sony, M.; Naik, S. Critical factors for the successful implementation of Industry 4.0: A review and future research direction. Prod. Plan. Control 2020, 31, 799-815. [CrossRef]

35. De Sousa Jabbour, A.B.L.; Jabbour, C.J.C.; Godinho Filho, M.; Roubaud, D. Industry 4.0 and the circular economy: A proposed research agenda and original roadmap for sustainable operations. Ann. Oper. Res. 2018, 270, 273-286. [CrossRef]

36. Moldavska, A.; Welo, T. The concept of sustainable manufacturing and its definitions: A content-analysis based literature review. J. Clean. Prod. 2017, 166, 744-755. [CrossRef]

37. Ford, S.; Despeisse, M. Additive manufacturing and sustainability: An exploratory study of the advantages and challenges. $J$. Clean. Prod. 2016, 137, 1573-1587. [CrossRef]

38. De Sousa Jabbour, A.B.L.; Jabbour, C.J.C.; Foropon, C.; Godinho Filho, M. When titans meet-Can industry 4.0 revolutionise the environmentally-sustainable manufacturing wave? The role of critical success factors. Technol. Forecast. Soc. Chang. 2018, 132, 18-25. [CrossRef]

39. Amankwah-Amoah, J. Emerging economies, emerging challenges: Mobilising and capturing value from big data. Technol. Forecast. Soc. Chang. 2016, 110, 167-174. [CrossRef]

40. Chung, M.; Kim, J. The Internet Information and Technology Research Directions based on the Fourth Industrial Revolution. KSII Trans. Internet Inf. Syst. 2016, 10, 1311-1320. [CrossRef]

41. Lin, D.; Lee, C.K.M.; Lau, H.; Yang, Y. Strategic response to Industry 4.0: An empirical investigation on the Chinese automotive industry. Ind. Manag. Data Syst. 2018, 118, 589-605. [CrossRef]

42. Stock, T.; Obenaus, M.; Kunz, S.; Kohl, H. Industry 4.0 as enabler for a sustainable development: A qualitative assessment of its ecological and social potential. Process Saf. Environ. Prot. 2018, 118, 254-267. [CrossRef]

43. Bonilla, S.H.; Silva, H.R.O.; Terra da Silva, M.; Franco Gonçalves, R.; Sacomano, J.B. Industry 4.0 and sustainability implications: A scenario-based analysis of the impacts and challenges. Sustainability 2018, 10, 3740. [CrossRef]

44. World Economic Forum. Drones and Africa's Future. Available online: https://www.weforum.org/events/world-economicforum-on-africa-2019/sessions/a0W0\$ $\backslash$ times\$00000FulrIUAR (accessed on 3 December 2019).

45. Naudé, W. Entrepreneurship, Education and the Fourth Industrial Revolution in Africa. IZA Discussion Papers, No. 10855, Institute of Labor Economics (IZA). Available online: http:/ /hdl.handle.net/10419/170839 (accessed on 3 December 2019). 
46. Jaschke, S. Mobile learning applications for technical vocational and engineering education: The use of competence snippets in laboratory courses and industry 4.0. In Proceedings of the 2014 International Conference on Interactive Collaborative Learning (ICL), Dubai, UAE, 3-6 December 2014; pp. 605-608. [CrossRef]

47. Sackey, S.M.; Bester, A. Industrial engineering curriculum in Industry 4.0 in a South African context. S. Afr. J. Ind. Eng. 2016, 27, 101-114. [CrossRef]

48. Kim, H.; Sefcik, J.S.K.; Bradway, C. Characteristics of qualitative descriptive studies: A systematic review. Res. Nurs. Health 2017, 40, 23-42. [CrossRef] [PubMed]

49. Sandelowski, M. What's in a name? Qualitative description revisited. Res. Nurs. Health 2010, 33, 77-84. [CrossRef] [PubMed]

50. Magilvy, J.K.; Thomas, E. A first qualitative project: Qualitative descriptive design for novice researchers. J. Spec. Pediatr. Nurs. 2009, 14, 298-300. [CrossRef]

51. Etikan, I.; Musa, S.A.; Alkassim, R.S. Comparison of convenience sampling and purposive sampling. Am. J. Theor. Appl. Stat. 2016, 5, 1-4. [CrossRef]

52. Neergaard, M.A.; Olesen, F.; Andersen, R.S.; Sondergaard, J. Qualitative description-the poor cousin of health research? BMC Med. Res. Methodol. 2009, 9, 1-5. [CrossRef]

53. Miguel, P.A.C. Qualitative research approach in production engineering-An assessment of a research project and a sample of master of science dissertations. Exacta 2011, 9, 197-206. [CrossRef]

54. Maguire, M.; Delahunt, B. Doing a thematic analysis: A practical, step-by-step guide for learning and teaching scholars. All Irel. J. Teach. Learn. High. Educ. 2017, 9, 3351-3364.

55. Braun, V.; Clarke, V. Using thematic analysis in psychology. Qual. Res. Psychol. 2006, 3, 77-101. [CrossRef]

56. Friese, S. Atlas ti 8 Widows User Manual. Available online: http://downloads.atlasti.com/docs/manual/atlasti_v8_manual_en. pdf (accessed on 5 June 2019).

57. Sandelowski, M. Whatever happened to qualitative description? Res. Nurs. Health 2000, 23, 334-340. [CrossRef]

58. Karre, H.; Hammer, M.; Kleindienst, M.; Ramsauer, C. Transition towards an Industry 4.0 state of the LeanLab at Graz University of Technology. Procedia Manuf. 2017, 9, 206-213. [CrossRef] 